\title{
Ziprasidone in the Treatment of Delusional Parasitosis
}

\author{
P. Contreras-Ferrer ${ }^{a} \quad$ N. Merino de Paz ${ }^{a} \quad$ M.R. Cejas-Mendez \\ M. Rodríguez-Martín ${ }^{a} \quad$ R. Souto ${ }^{b} \quad$ M. García Bustínduy ${ }^{a}$ \\ Departments of ${ }^{\mathrm{a}}$ Dermatology and ${ }^{\mathrm{b}}$ Psychiatry, Hospital Universitario de Canarias, \\ La Laguna, Spain
}

Key Words

Delusional parasitosis $\cdot$ Antipsychotics $\cdot$ Ziprasidone $\cdot$ Extrapyramidal symptoms

\begin{abstract}
Delusional parasitosis is characterized by a patient's fixed false belief of being infested with parasites or small creatures. The first-line treatment options are typical antipsychotics such as pimozide. However, the accompanying extrapyramidal side effects might limit their use. We report on a patient with a good response to pimozide combined with ziprasidone. Ziprasidone is an atypical antipsychotic drug with a lower risk of extrapyramidal symptoms; thus, it might be considered a good first or second treatment option for delusional parasitosis.
\end{abstract}

\section{Introduction}

Delusional parasitosis (DP), also known as 'Ekbom syndrome', is a type of psychosis. DP patients believe that their skin is infested by parasites that underlie their cutaneous surface $[1,2]$. They use to carry pieces of skin or 'infected' clothes in matchboxes or in adhesive tape to prove their beliefs. DP is a somatic type of delusional disorder. Secondary organic causes might be investigated before the final diagnosis (neurologic, cardiovascular, renal, liver or endocrine diseases, nutritional disorders, infectious diseases, malignancy, substance abuse and pharmacological treatments). DP is the most common form of monosymptomatic hypochondriacal psychosis. The etiology of this disorder is not yet well known. However, one theory suggests that patients with DP have an excess of extracellular dopamine within the striatum nucleus of the brain. The good response to pimozide treatment, which acts as an antagonist dopamine, could be explained by this theory $[3,4]$. 


\section{Case Report}

A 73-year-old patient was referred to our Dermatology Department in July 2010 presenting with deep linear ulcers on the left side of the face ( $\underline{\text { fig. 1 }}$ ), right arm and right side of the abdomen (fig. 2 ). She had a personal history of diabetes, primary bile cirrhosis and ischemic cerebrovascular attack (left medial cerebral artery) with right-sided paralysis. The lesions began in 2001 with a lip erosion and they have become more severe around the last month before admission. During the years 2005 and 2006, the patient was referred several times with severe pruritus without evident cutaneous primary lesions. The same itching sensation was reported by her husband, especially at night. They both have been treated under the clinical suspicion of scabies. Their skin became very irritated, and the itch was persistent. They needed topical and oral steroids as well as antihistamines.

DP was first suspected in 2007 as the patient insisted that she had an infection underlying her skin. A cutaneous biopsy was performed and showed unspecific changes on the dermis and epidermis. She was referred to our Psychiatry Department, where a delirious disorder was suspected as well. The patient's ulcers enlarged when she tried to find the parasites. Her husband and one of their sons felt also infected.

In order to isolate the patient from her family and her family from her, we decided to treat her as an inpatient at the psychiatric ward. She was treated as a true psychosis using olanzapine; however, this treatment was ineffective, and pimozide was started in association with ziprasidone.

Several adverse extrapyramidal effects appeared, and an anticholinergic drug was needed (dantrolene) for control. Two weeks later, the patient finally felt that 'the infection was not present anymore'.

\section{Discussion}

DP is a psychotic disorder that might be difficult to diagnose for the physician. It is very important to ensure that no organic disorder is underlying the delusions [5]. In fact, our case presented some of the different causes for itching appearance. Nevertheless, the morphology and localization of the erosions and ulcers were very typical of DP.

Furthermore, the treatment of DP is also difficult because patients have a fixed unshakeable belief that they are infested and they are searching for an antibiotic, antiseptic or an antiparasitic drug [6]. Antipsychotic drugs are not easy to introduce and maintain in these patients, although they are needed to control the disease.

Our patient was admitted because of the evidence of 'folie à deux' [7] induced in her husband and to ensure the adherence to treatment. In patients with delusions of infestation, the typical antipsychotics, such as pimozide, have traditionally been the first-line options $[1,2]$. Their extrapyramidal side effects are well known and, in fact, they appeared in our patient. The evidence from some case reports has indicated the beneficial effects of atypical antipsychotics such as olanzapine [8,9] or risperidone [10, 11]. As our patient had not responded completely to this drug, ziprasidone was additionally administered, showing good results.

We report a clinical case of DP treated with ziprasidone, an atypical antipsychotic with a lower risk of extrapyramidal symptoms. Aripiprazole has also been shown to provide promising results [12]. However, as DP cases are not common, it is difficult to study patient series of different treatments. Patients with psychodermatological disorder are not easy to identify, diagnose and treat. However, a close collaboration between clinical colleagues may help to improve treatment of DP patients. 


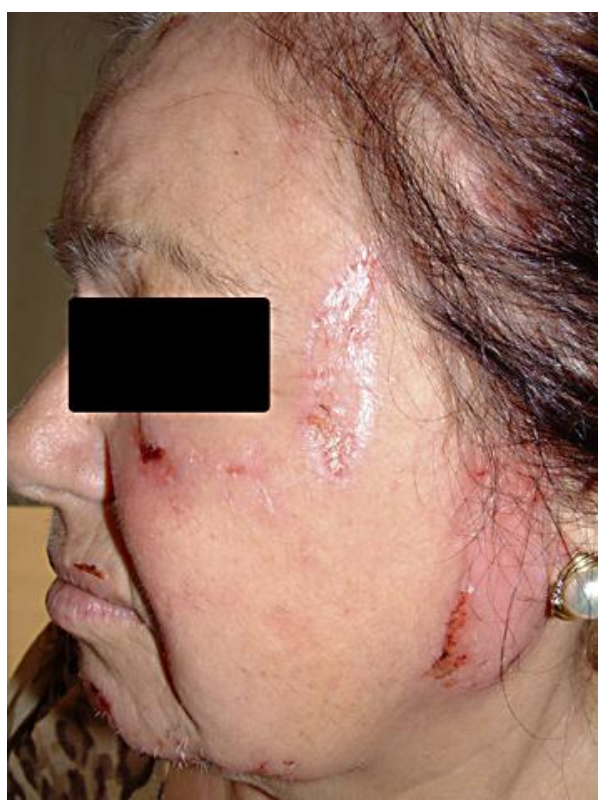

Fig. 1. Multiple linear erosions covered with a hemorrhagic crust on the left side of the face.

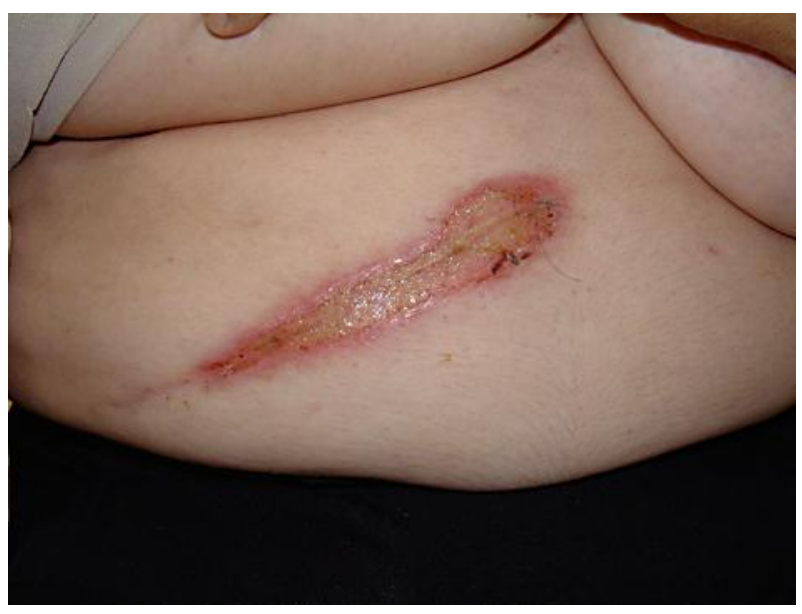

Fig. 2. Deep linear ulcer on the right side of the abdomen. 


\section{References}

1 Koo JY, Pham CT: Psychodermatology. Practical guidelines on pharmacotherapy. Arch Dermatol 1992;128:381-388.

-2 Freudenmann RW, Lepping P: Delusional infestation. Clin Microbiol Rev 2009;22:690-732.

-3 Huber M, Karner M, Kirchler E, Lepping P, Freudenmann RW: Striatal lesions in delusional parasitosis revealed by magnetic resonance imaging. Prog Neuropsychopharmacol Biol Psychiatry 2008;32:19671971.

4 Huber M, Kirchler E, Karner M, Pycha R: Delusional parasitosis and the dopamine transporter. A new insight of etiology? Med Hypotheses 2007;68:1351-1358.

5 Aw DC, Thong JY, Chan HL: Delusional parasitosis: case series of 8 patients and review of the literature. Ann Acad Med Singapore 2004;33:89-94.

-6 Ahmad K, Ramsay B: Delusional parasitosis: lessons learnt. Acta Derm Venereol 2009;89:165-168.

$\rightarrow 7$ Cordeiro Q Corbett CE: Delusional parasitic infestation and folie à deux: case report (in Portuguese). Arq Neuropsiquiatr 2003;61:872-875.

8 Freudenmann RW: A case of delusional parasitosis in severe heart failure. Olanzapine within the framework of a multimodal therapy (in German). Nervenarzt 2003;74:591-595.

$\checkmark 9$ Le L, Gonski PN: Delusional parasitosis mimicking cutaneous infestation in elderly patients. Med J Aust 2003;179:209-210.

10 Shah AJ, Pervez YP: Risperidone long acting injection in delusional parasitosis. German J Psychiatry 2009;12:35-37.

11 Gallucci G, Beard G: Risperidone and the treatment of delusions of parasitosis in an elderly patient. Psychosomatics 1995;36:578-580.

12 Koblenzer CS: The current management of delusional parasitosis and dermatitis artefacta. Skin Therapy Lett 2010;15:1-3. 